\title{
Giant liposarcoma of the esophagus
}

\author{
Annie Beaudoin MD, Charles Journet MD, Alain Watier MD, \\ Charles-Jacques Mongeau MD, Michel Chagnon MD, René Beaudry MD
}

\begin{abstract}
A Beaudoin, C Journet, A Watier, C-J Mongeau, M Chagnon, R Beaudry. Giant liposarcoma of the esophagus. Can J Gastroenterol 2002;16(6):377-379.

Liposarcomas of the gastrointestinal tract are exceedingly rare. Only nine cases of esophageal involvement have been described. A 68-year-old woman presented with an episode of vomiting followed by extrusion of a polypoid mass from the mouth. This 10th case of esophageal liposarcoma is the first in the literature to report a recurrence 25 years after the first episode.
\end{abstract}

\section{Un liposarcome géant de l'œesophage}

RÉSUMÉ : Les liposarcomes du tractus gastro-intestinal sont d'une extrême rareté. Seulement neuf cas d'atteinte œsophagienne ont été décrits. Une femme de 68 ans s'est présentée après une crise de vomissements suivie de l'expulsion d'une masse polypoïde par la bouche. Ce dixième cas de liposarcome œsophagien est le premier dans la documentation scientifique à faire état d'une récurrence 25 ans après un premier épisode.

Key Words: Deglutition disorders; Esophageal neoplasms; Liposarcoma

L ipomatous tumours are rarely seen in the gastrointestinal tract. They have an incidence of $0.1 \%$ to $5.8 \%$ at autopsy and are predominantly found in the terminal ileum and colon (1). The esophagus is the least frequent alimentary tract location, comprising only $1.2 \%$ to $1.5 \%$ of all gastrointestinal lipomas (2).

A variety of sarcomatous tumours of the esophagus are occasionally seen. These tumours comprise less than $0.5 \%$ of all primary malignant esophageal tumours, which include fibrosarcoma, leiomyosarcoma, rhabdomyosarcoma and car- cinosarcoma (3). Liposarcomas of the esophagus are even rarer, with only nine reported cases in the literature (3-9).

We report a woman who developed a liposarcoma of the upper esophagus, which is presumed to be a recurrence of a primary tumour that had been resected 25 years earlier.

\section{CASE PRESENTATION}

A 68-year-old woman had a four-month history of progressive dysphagia, initially to solid food and then to liquids. An upper endoscopy demonstrated a polypoid mass of the 


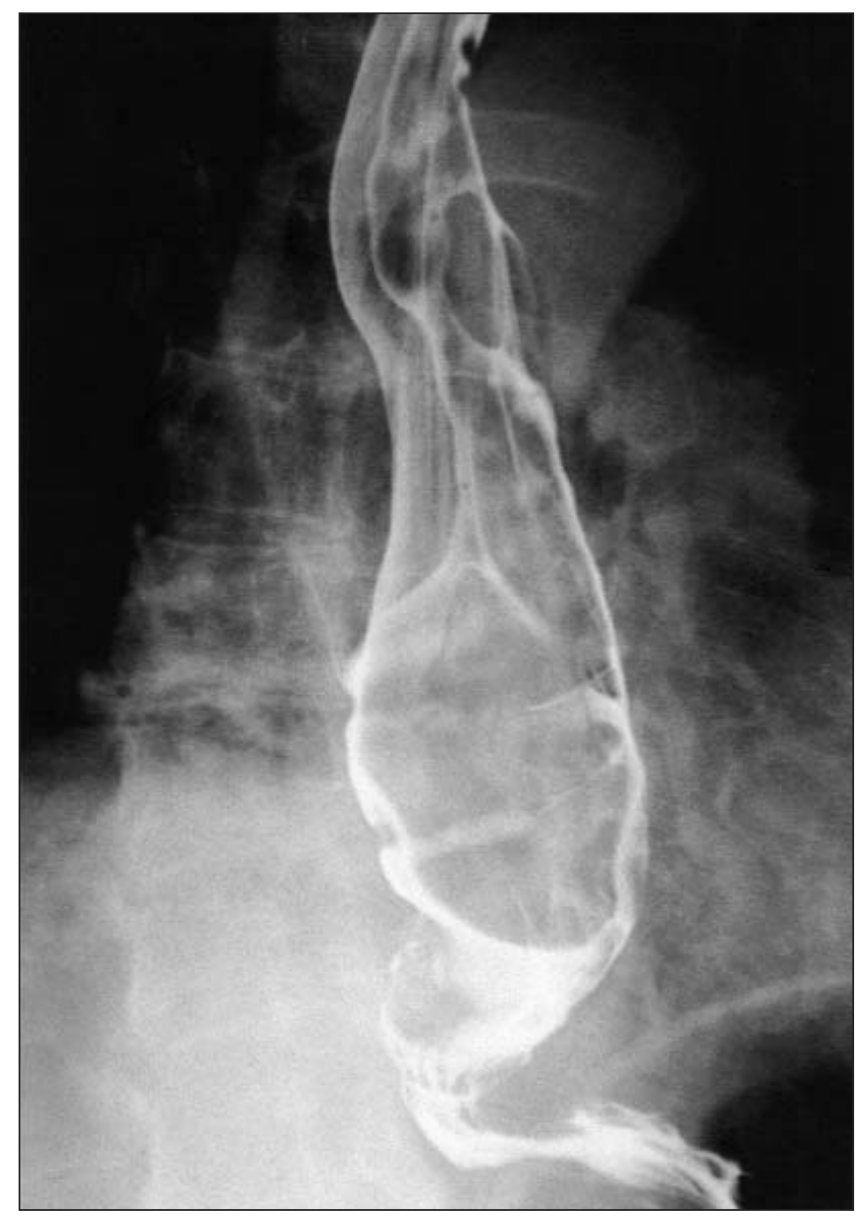

Figure 1) Upper gastrointestinal series demonstrating an esophageal polyp, several centimetres in length, starting at the proximal esophagus and extending inferiorly at the distal third

proximal esophagus, extending from 18 to $31 \mathrm{~cm}$. An endoluminal esophageal polyp was seen on upper gastrointestinal series, while computed tomography scan demonstrated that the polyp had a lipomatous component (Figures 1,2). While waiting to undergo excision surgery, the patient presented with an episode of vomiting, with extrusion of the polypoid mass from her mouth (Figure 3). Because of the fear of suffocation, the polyp was immediately excised transorally while the patient was under general anesthesia. Her preoperative symptoms resolved immediately after surgery.

The excised specimen consisted of an $8.5 \times 4.5 \times 3 \mathrm{~cm}$ polypoid mass with bosselated focally ulcerated surface. Cut section demonstrated yellowish-white areas that were more or less completely circumscribed by greyish fibrousappearing tissue (Figure 4). A lobulated adipose tumour with fibrous septae was seen on microscopic examination. The cellular component was predominantly made up of mature adipocytes of irregular size and shape, as well as occasional, marked nuclear atypia. The presence of occasional bona fide lipoblasts was confirmed by nucleocytoplasmic immunostaining with S-100 protein (Figure 5). Spindle and myxoid patterns were also present. Therefore,

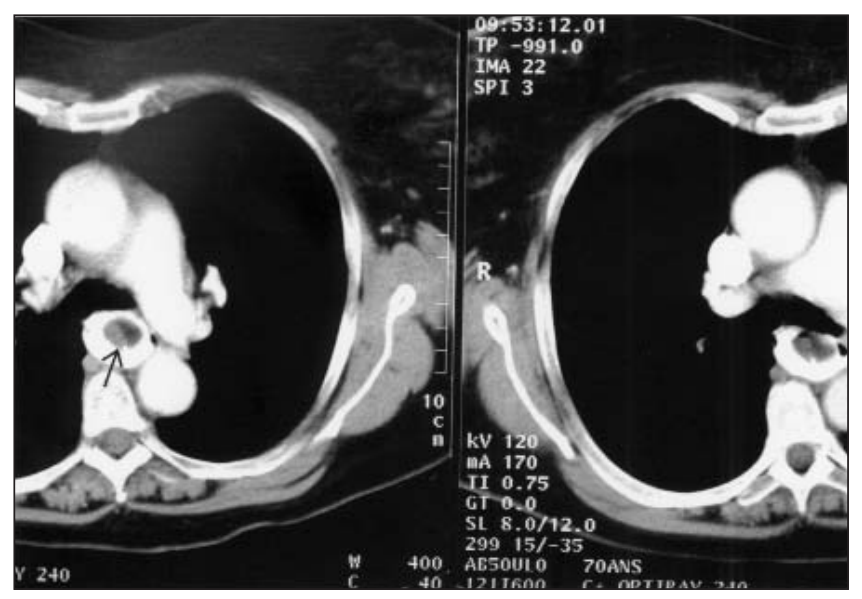

Figure 2) Computed tomography with oral contrast shows a well defined $3 \times 3 \times 16 \mathrm{~cm}$ endoluminal lesion, with no transmural extension (black arrow). Of note is the presence of a lipomatous component in the lesion (density measurement: $-150 \mathrm{HU}$ )

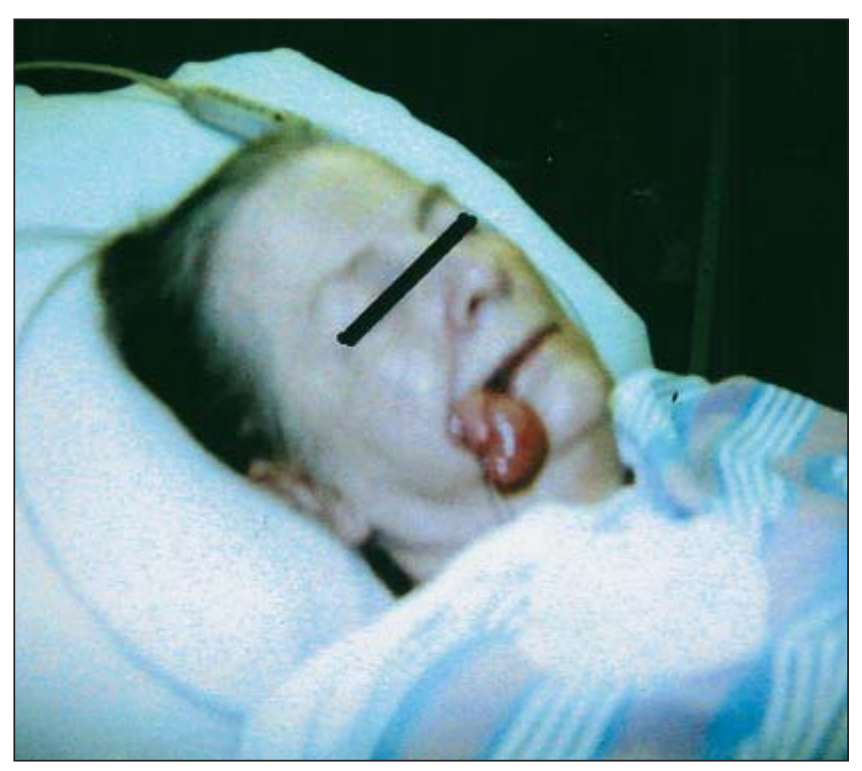

Figure 3) Extrusion of a polypoid mass from the mouth of a patient with a giant esophageal liposarcoma, after presenting with an episode of vomiting

the histological diagnosis was well differentiated, lipomalike liposarcoma extending to the margin of resection.

The patient is currently awaiting a second surgery for a more radical resection. Of note, she had presented with exactly the same symptoms 25 years earlier while working as a missionary in Africa. At that time, after a vomiting episode, a mass that hung from her mouth to her neck had been extruded. According to the patient, she had undergone a transoral excision. It was not possible to retrieve more information from the foreign hospital where this event occurred. She had no follow-up or pathology results. It is supposed that the first episode was a lipomatous tumour, and most likely a liposarcoma. 


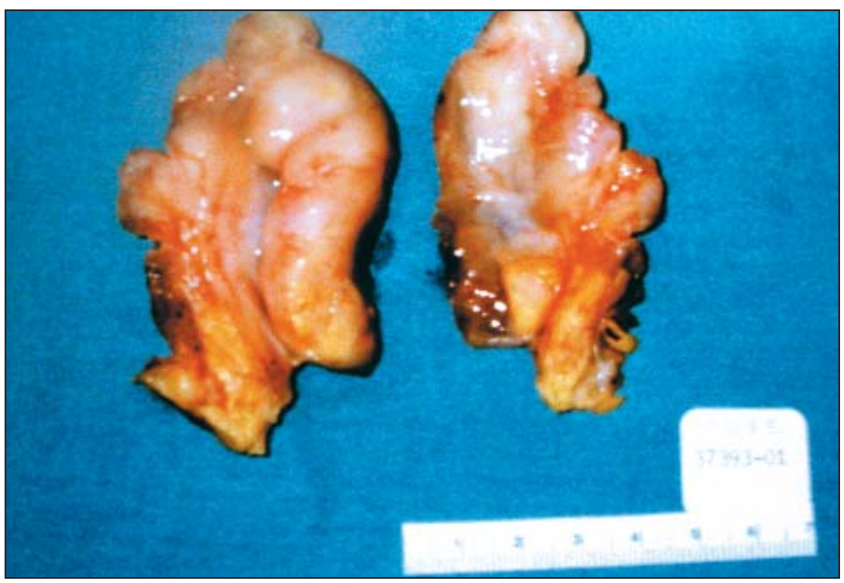

Figure 4) Cut gross specimen of a polypoid mass excized from a patient with a giant esophageal liposarcoma

This is the first case in the literature to report a possible recurrence of a primary liposarcoma of the esophagus 25 years after a first episode.

\section{DISCUSSION}

Liposarcomas comprise $9.8 \%$ to $16 \%$ of all soft tissue sarcomas (5). These are the most common sarcomas of the lower extremities and retroperitoneum (3). Esophageal liposarcomas are very rare, slowly growing tumours that arise from the soft tissue layers of the esophagus. Those tumours are believed to originate from primitive mesenchymal cells rather than mature adipose tissue (6). The histological types of liposarcomas are well differentiated, myxoid, round cell and pleomorphic (10).

All patients with esophageal liposarcomas reported in the literature complained of dysphagia $(5,8)$. Other symptoms may include weight loss, foreign body sensation and, rarely, gastrointestinal bleeding or asphyxia. There are often surprisingly few symptoms, until the tumour has attained a considerable size.

Barium swallow and upper endoscopy series demonstrate nonspecific features and only define the presence of a polypoid esophageal tumour (7). The accuracy of the diagnosis is enhanced by computed tomography scan and magnetic resonance imaging because of the fatty nature of the lesion (8). However, relying solely on these methods could lead to misdiagnosis because of their inability to distinguish between lipomas and liposarcomas. Histological examination is often the most reliable method for making the correct diagnosis, although the pathological literature on this subject is sparse.

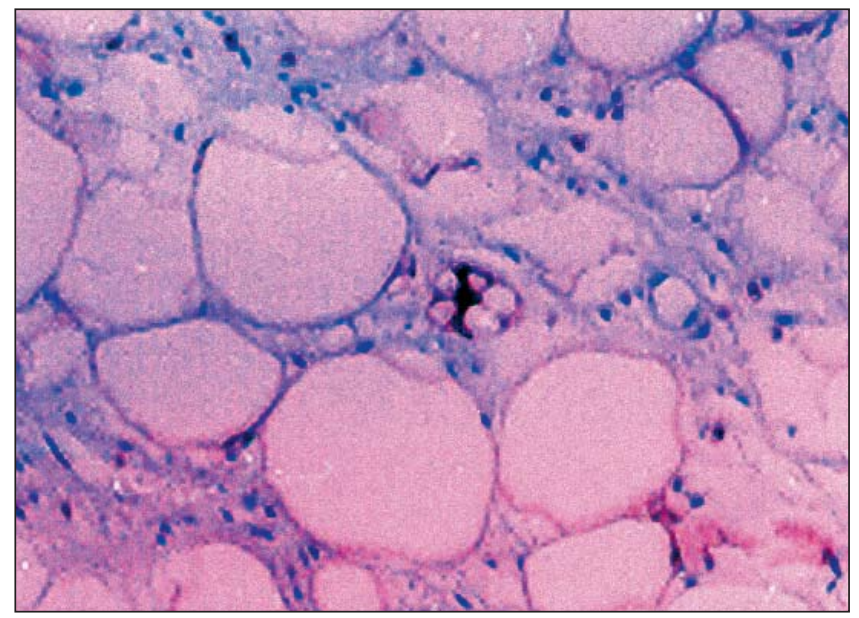

Figure 5) Nucleocytoplasmic immunostaining of a section of the polypoid mass shown in Figure 4, demonstrating well differentiated liposarcoma (original magnification $\times 160$ )

It is critical to obtain histologically free margins on surgical resection, considering the high local recurrence rate (5). Liposarcomas of all sites have been associated with other primary malignant tumours in approximately $12 \%$ of cases in Hajdu's series (11). Our patient had no other known malignant disease. A thorough, long term follow-up must be planned for patients with this type of tumour.

\section{REFERENCES}

1. Feldman M. An apprasial of associated conditions occurring in autopsied cases of lipoma of the gastrointestinal tract. Am J Gastroenterol 1961;36:413-6.

2. Fernandez MJ, Davis RP, Nora PF. Gastrointestinal lipomas. Arch Surg 1983;118:1081-3.

3. Mansour KA, Fritz RC, Jacobs DM, Vellios F. Pedunculated liposarcoma of the esophagus: a first case report.

J Thorac Cardiovasc Surg 1983:86:447-50.

4. Temes R, Quinn P, Davis M, et al. Endoscopic resection of esophageal liposarcoma. J Thorac Cardiovasc Surg 1998;166:365-7.

5. Mandell DL, Brandwein MS, Woo P, Som PM, Biller HF, Urken ML. Upper aerodigestive tract liposarcoma: report on four cases and literature review. Laryngoscope 1999;109:1245-52

6. Cooper GJ, Boucher NR, Smith JHF, Thorpe JAC. Liposarcoma of the esophagus. Ann Thorac Surg 1991;51:1012-3.

7. Boggi U, Viacava P, Naccarato AG, et al. Giant pedunculated liposarcomas of the esophagus: literature review and case report. Hepatogastroenterology 1997;44:398-407.

8. Ruppert-Kohlmayr AJ, Raith J, Friedrich G, Regauer S, Preidler KW, Szolar DH. Giant liposarcoma of the esophagus: radiological findings. J Thorac Imag 1999;14:316-9

9. Salis GB, Albertengo JC, Bruno M, et al. Pedunculated liposarcoma of the esophagus. Dis Esophagus 1998;11:68-71.

10. Stewart MG, Schwartz MR, Alford BR. Atypical and malignant lipomatous lesions of the head and neck. Arch Otolaryngol Head Neck Surg 1994;120:1151-5.

11. Hajdu SI. Pathology of soft tissue tumors. Philadelphia: Lea \& Febiger, 1979. 


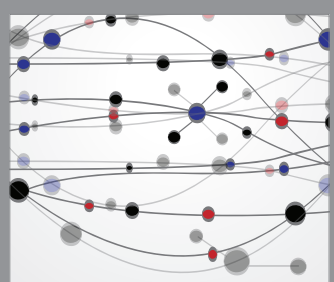

The Scientific World Journal
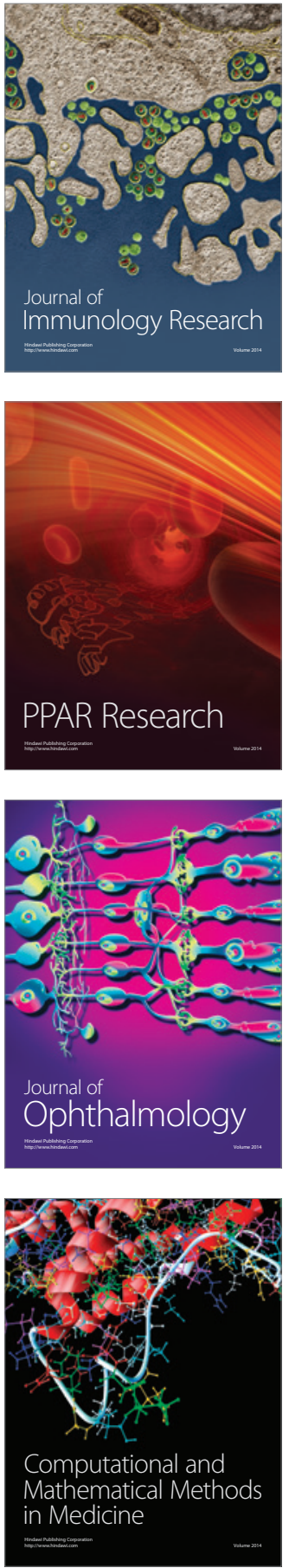

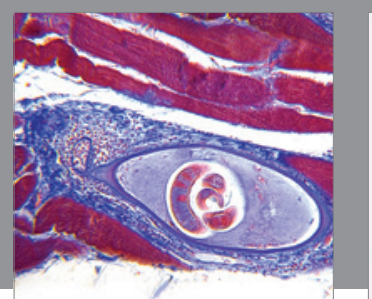

Gastroenterology Research and Practice

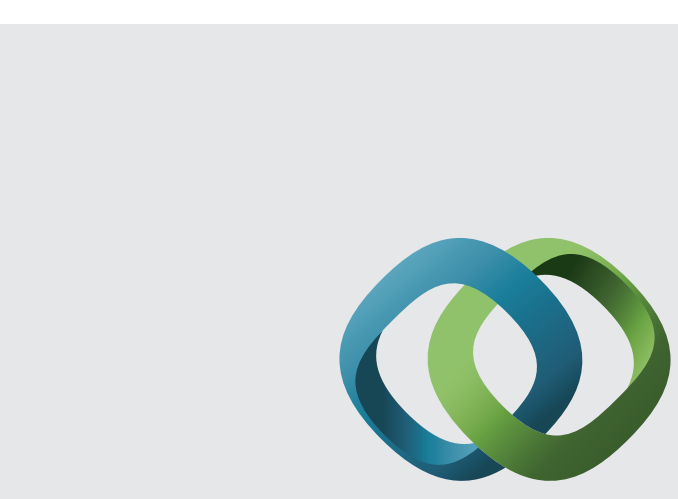

\section{Hindawi}

Submit your manuscripts at

http://www.hindawi.com
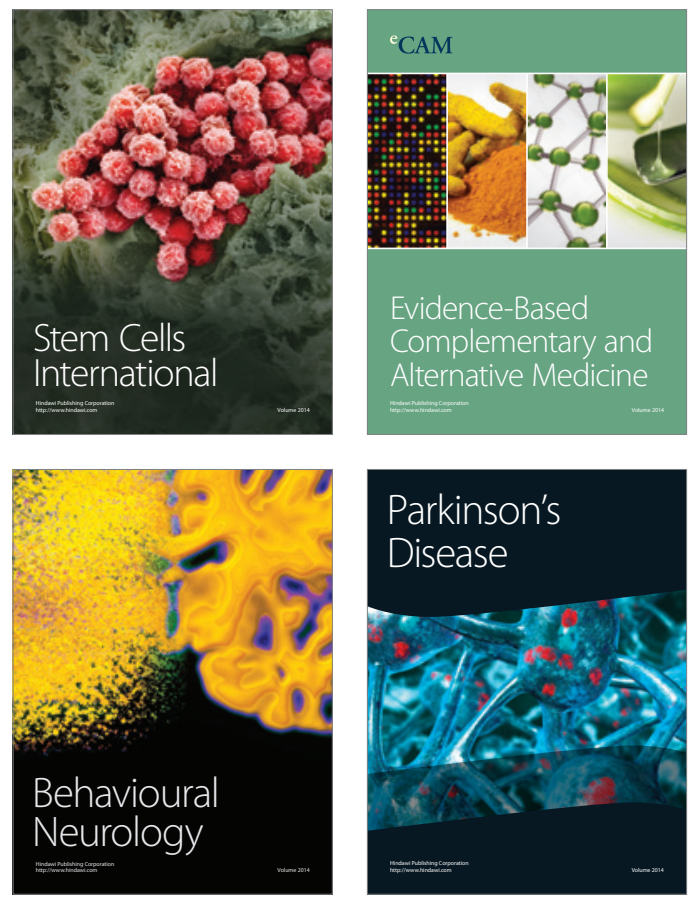
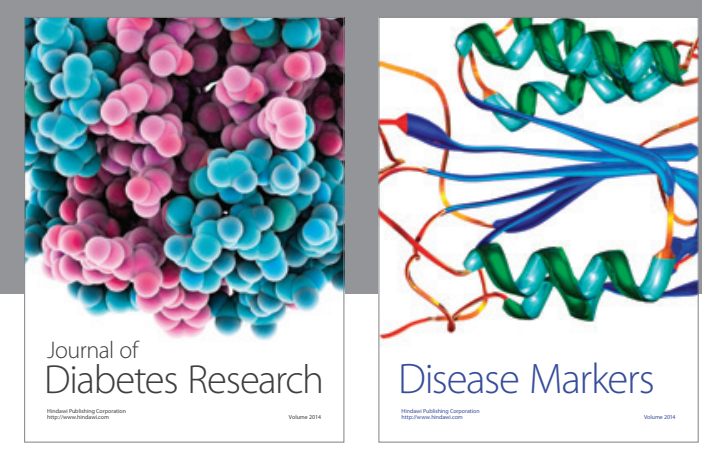

Disease Markers
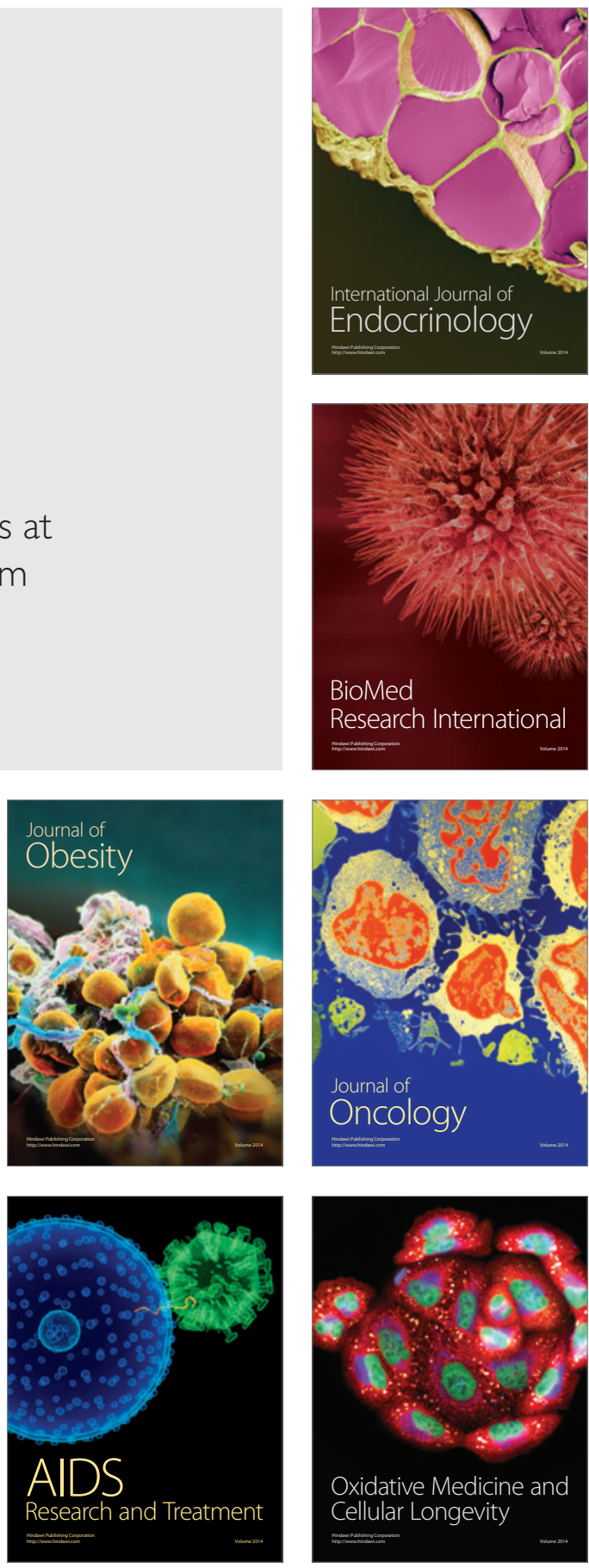